\title{
WORKSHOP NERVE GLIDING EXERCISE DAN PEMBERIAN ULTRA SOUND (US) TERHADAP PENURUNAN NYERI PADA KASUS CARPAL TUNNEL SYNDROME DI GRANDMED LUBUK PAKAM
}

\section{Raynald Ignasius Ginting ${ }^{1 *}$, Sabirin Berampu ${ }^{1}$, Siti Sarah Bintang ${ }^{1}$, Ni Nyoman Ayu Tamala Hardis ${ }^{1}$, Engraini Teja ${ }^{1}$}

\author{
${ }^{1}$ Program Studi Fisioterapi, Institut Kesehatan Medistra Lubuk Pakam \\ Program Studi D3 Fisioterapi, Institut Kesehatan Medistra Lubuk Pakam \\ JIn. Sudirman No.38 Lubuk Pakam, Kabupaten Deli Serdang, \\ Sumatera Utara - Indonesia \\ *email korespondensi author: enalsius13@gmail.com
}

DOI $10.35451 /$ jpk.v1i1.747

\begin{abstract}
Abstrak
Permasalahan yang sering terjadi bagi para pekerja yaitu Carpal tunnel syndrome (CTS). Carpal tunnel syndrome merupakan salah satu gangguan pada tangan akibat terjepitnya saraf medianus di terowongan karpal, baik akibat adhesi maupun kelainan tulan-tulang kecil tangan. Saraf medianus menginervasi pada ibu jari, jari telunjuk, jari tengah dan sebagian pada jari manis, sehingga dapat dirasakan nyeri maupun paratesia didaerah tersebut. Salah satu cara terapi non-farmakologi yang bisa digunakan pada CTS ini, melalui pemberian nerve gliding exercise. Nerve gliding exercise dan pemberian modalitas ultra sound (US) dilakukan dengan tujun untuk mengurangi penekanan pada pergelangan tangan sehingga nyeri dapat berkurang. Hasil dari kegitanan pengabdian ini menyatakn bahwa sebanyak 94\% peserta sebagai fisioterapis telah memahami dan mampu menggunakan nerve gliding exercise dan Ultra Sound (US) terhahap penurunan nyeri pada kasus CTS.
\end{abstract}

Kata kunci: Nerve Gliding Exercise; Ultra Sound; Carpal Tunnel Syndrome

\begin{abstract}
The problem that often occurs for workers is Carpal tunnel syndrome (CTS). Carpal tunnel syndrome is a disorder of the hand due to compression of the median nerve in the carpal tunnel, either due to adhesions or abnormalities of the small bones of the hand. The median nerve innervates the thumb, index finger, middle finger and part of the ring finger, so that pain and parathesia can be felt in these areas. One way of nonpharmacological therapy that can be used in CTS is through the provision of nerve gliding exercise. Nerve gliding exercise and the administration of ultra sound (US) modality are done with the aim of reducing pressure on the wrist so that pain can be reduced. The results of this service activity stated that as many as $94 \%$ of participants as physiotherapists had understood and were able to use nerve gliding exercise and Ultra Sound (US) for pain reduction in CTS cases.
\end{abstract}

Keywords: Nerve Gliding Exercises; Ultra Soud(US); Carpal Tunnel Syndrome

\section{Pendahuluan}

Perkembangan zaman dalam segala bidang yang semakin kuat dan ketat maka dibutuhkan kualitas sumber daya manusia yang baik dan cukup bermutu. Sumber daya manusia dengan cukup berkualitas pun jika mengalami gangguan kesehatan dapat menurunkan 
Received: 16 June 2021 :: Accepted: 16 June 2021 :: Published: 30 June 2021

produktivitas kerja. Permasalahan yang sering terjadi pada dunia saat ini adalah berkurangnya produktivitas pekerja akibat penyakit akibat kerja salah satunya yaitu caropal tunnel syndrome. Carpal tunnel syndrome merupakan salah satu gangguan pada tangan akibat terjepitnya saraf medianus di terowongan karpal, baik akibat adhesi maupun kelainan tulan-tulang kecil tangan. Saraf medianus menginervasi pada ibu jari, jari telunjuk, jari tengah dan sebagian pada jari manis, sehingga dapat dirasakan nyeri maupun paratesia didaerah tersebut (Bahrudin et al, 2015).

International labour organization mengungkapkan bahwa CTS selalu terjadi dalam setiap penyakit akibat kerja dibeberapa negara. Kasus CTS di Cina mengalami peningkatan sebesar $30 \%$ (Bahrudin, et al, 2015. Angka kasus CTS akibat kerja sekitar 90\% dari berbagai neuropati lainnya. Hampir disetiap tahunnya kejadian CTS mencapai 267 dari 100.000 populasi dengan prevalensi $6 \%$ pada laki-laki dan $9.2 \%$ pada perempuan (Sekarsari, et al, 2017).

Di Indonesia prevalensi kasus CTS dalam masalah kerja belum pasti diketahui. Karena sampai tahun 2001, sangat sedikit dilaporkan kasus akibat kerja, karena sulitnya diagnosis. Penelitian pada pekerjaan dengan resiko tinggi pada pergelangan tangan dan tangan melaporkan prevalensi CTS antara 5,6\% sampai dengan $15 \%$, (Salawati, 2014).

Fisioterapi sebagai salah satu ilmu di bidang kesehatan dapat berperan dalam bidangnya. Dimana fisioterapi dapat menyelenggarakan pelayanan kesehatan secara professional, $y$ ang bertanggung jawab atas kesehatan individu, keluarga dan masyarakat, khususnya dalam masalah kapasitas fisik dan kemampuan fungsional dengan penanganan secara manual, pralatan ( fisik, elektroterapeutik dan secara mekanis). Sehingga diupayakan penderita mampu memenuhi kebutuhan hidupnya secara mandiri dan mampu produktif tanpa dihalangi oleh permasalahan-permasalahan kesehatan yang ada (Depkes RI, 2013).
Penatalaksanaan CTS bisa dengan terapi medikalmentosa maupun terapi konservatif. Tetapi dalam beberapa kasus yang beraat perlu dipertimbangkan tindakan operasi. berdasarkan survey yang ada CTS banyak dialami oleh pekerja, sehingga dalam penanganannya perlu dilihat dari status ekonominya. Terapi konservatif dapat menjadi alternatif dalam penanganan CTS. Dari beberapa terapi konsevatif nerve gliding exercise merupakan jenis terapi yang sangat sering digunakan (Kim S, 2015)

Nerve gliding exercise merupakan salah satu teknik konservatif fisioterapi yang dilakukan dengan tujuan mengulur tendon dan saraf pada pergelangan tangan sehingga dapat mengurangi adhesi dan mengurangi rasa sakit, (Kaur, 2016). Nerve gliding exercise dianggap memiliki beberapa efek yaitu meningkatkan aliran pembuluh darah vena pada saraf medianus, menurunkan tekanan didalam tunnel dan meregangkan perlengketan (BallesteroPérez et al, 2017).

Ultra Sound (US) merupakan salah satu modalitas fisioterapi yang menggunakan gelombang suara dengan frekuensi lebih dari $20.000 \mathrm{~Hz}$ dengan panjang gelombangnya $1,5 \mathrm{~mm}$. US ini memberikan panas lokal untuk kapsul sendi, tendon, ligament dan otot sehingga dapat menigkatkan aktivitas sel dan vasodilatasi darah dan juga memfasilitasi transportasi metabolic ke jantung sehingga mengakiatkan penurunan iritasi ujung saraf dan nyeri pun berkurang. Efek panas juga dapat menyebabkan elastisitas dan mengurangi viskositas serat kolagen sehingga dapat meningkatkan fleksibilitas gerk sendi. Sehingga dapat meningakatkan kemampuan aktivitas fungsional. (Prentice, 2009).

Dalam pengabdian ini, yang dilakukan untuk mengetahui pengaruh penambahan nerve gliding exercise dan ultra sound terhadap penurunan nyeri CTS, Yang telah membuktikan bahwa adanya pengaruh penambahan nerve gliding exercise terhadap penurunan nyeri CTS (Rica, 2013).

Berdasarkan survey awal di rumah sakit Grandmed lubuk pakam bahwa 
Received: 16 June 2021 :: Accepted: 16 June 2021 :: Published: 30 June 2021

pasien CTS yang berkunjung ke rumah sakit grandmed lubuk pakam sekitar 17 pasien pada setiap bulannya. Selama ini pasien CTS tidak diberikan penanganan nerve gliding exercise dan ultra sound. Berdasarkan latar belakang yang dikemukakan di atas dan ketertarikan penulis untuk mengetahui lebih lanjut mengenai manfaat nerve gliding exercise dan modalitas ultra sound pada kasus CTS. Maka penulis membuat pengabdian dalam bentuk worksop nerve gliding exercise dan pemberian ultra sound terhadap penurunan nyeri pada pasien CTS di Poli Fisioterapi Rs Grandmed Lubuk Pakam Tahun 2020".

\section{Metode}

Kegiatan pengabdian ini dilakukan melalui workshop dengan menggunakan metode ceramah, tanya jawab dan demonstrasi. Alat ukur penurunan nyeri yang digunakan adalah Visual Analog Scale (VAS). Sebelum dilakukan pengukuran penurunan nyeri pada kelompok yang diberikan nerve gliding exercise dan ultra sound (us).

Langkah-langkah

dalam

pengabdian ini sebagai berikut:

1. Tahap persiapan

Prosedur asuhan dicatat dalam rekam fisioterapi dan rekam medik Rumah Sakit dengan contoh permulir terlampir. Peneliti bekerja sama dengan pasien yang berkunjung di Rumah Sakit.

2. Pemilihan responden

Responden yang dipilih adalah pasien yang datang ke poli fisioterapi Rumah Sakit Grandmed Lubuk Pakam yang sesuai dengan kriteria inklusi dan esklusi.

3. Tahap pelaksanaan tindakan

Peneliti akan meengatur posisi pasien senyaman mungkin di bed. Kemudian psosisi tangan pasien dirileksasikan. Lalu fisioterapi menekuk siku dan ditambah palmar fleksi pada pergelangan tangan. Kemudian siku di ekstensikan dengan memberikan genggaman pada pergelangan tangan, lalu siku di ekstensikan dengan memberikan gerakan abduksi dengan bantuan dorongan pada paha, dan meminta responden mengarahkan leher kearah yang berlawanan. Dimana dosis pemberikan nerve gliding exercise ini 5 detik tananan dan dilkukan sebanyak 5 sesi. Setiap sesi diulang sebanyak 10 kali. Setelah diberikan terapi latihan, lalu sampel diberikan ultra sound di daerah pergelangan tangannya. Daerah yang kan diterapi akan diberikan gel terlebih dahulu. Lalu peneliti menghidupkan alat us dengan frekuensi 0,8 sampai $3 \mathrm{Mz}$. Lalu tranducer di arahkan di daerah tangan yang sudah diberikan gel tersebut lalu tranducer digerakkan sesuai arah serbut otot. Dan pemakaian modalitas ini dilakukan selama 10-15 menit.
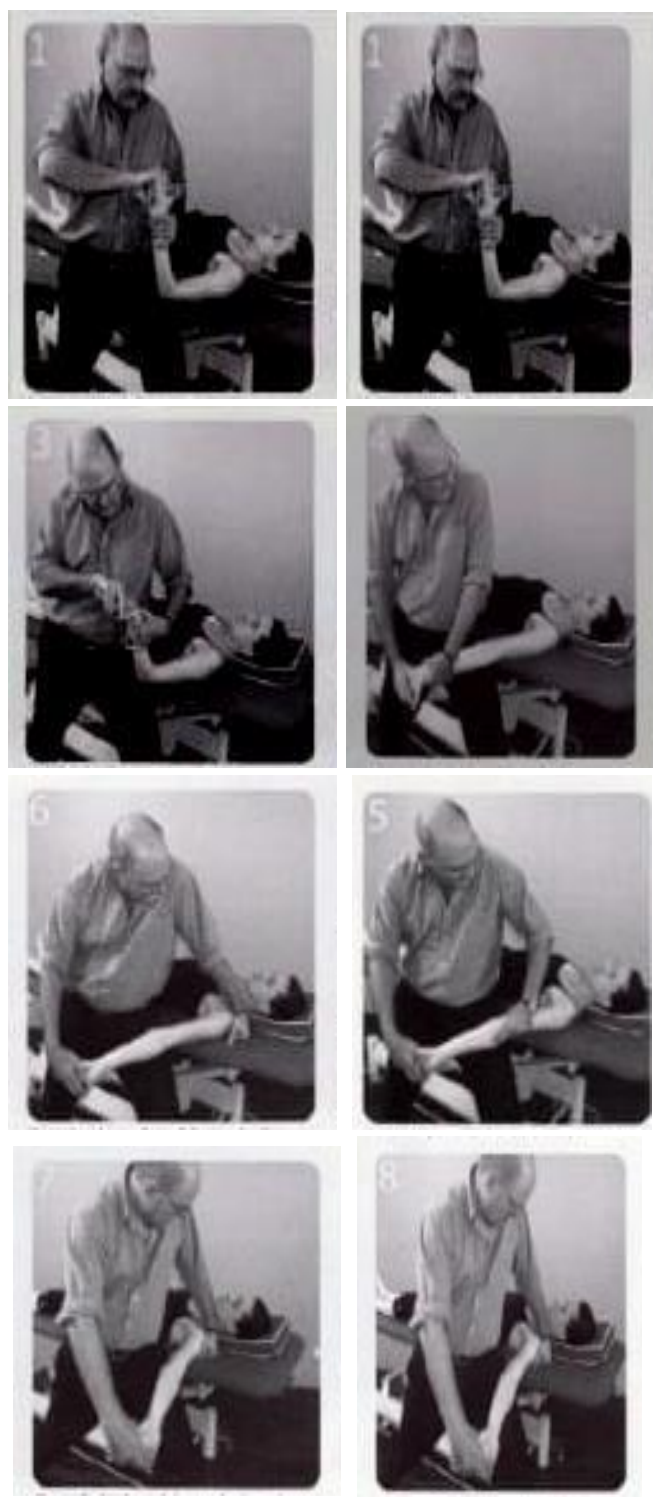

Gambar 1. Gerakan dari nerve gliding exrcise 


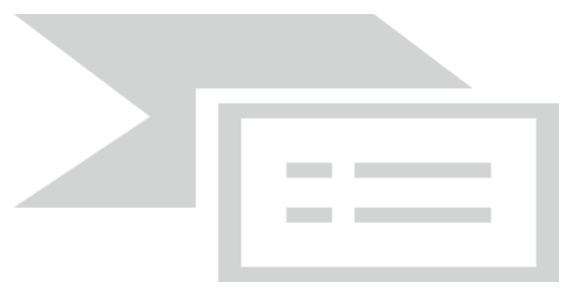

Gambar 2. Ultra Sound

Pengabdian melakukan evaluasi terhadap responden dan tindak lanjut kepada kepala ruangan.

\section{Hasil dan Pembahasan}

Kegiatan ini dilakukan untuk meningkatkan pengetahuan fisioterapis dalam menurunkan skala nyeri Carpal Tunnel Syndrome dengan menggunakan Neruve Gliding Exercise dan Ultra Sound (US). Hasil yang telah dicapai dalam pengabdian ini adalah sebagai berikut:

1. Materi dapat dipahami dan direspon baik oleh peserta, hal ini dapat dilihat melalui banyaknya pertanyaan dan tanggapan yang muncul dari peserta.

2. Peserta mampu menerapkan Penggunaan nerve gliding exercise dan ultra sound (us)

Secara umum hasil pengabdian meliputi aspek-aspek:

1. Ketercapaian tujuan kegiatan

Terjadi peningkatan kemampuan fisioterapis dalam menerapkan Penggunaan nerve gliding exercise dan ultra sound (us) Terhadap Penurunan Nyeri, .

2. Ketercapaian target materi

Materi yang disampaikan sudah sangat baik, sebab telah disampaikan secara keseluruhan. Materi yang disampaikan dengan didukung oleh evidence based.

3. Kemampuan peserta

Kemampuan peserta dapat diukur dari pemahaman dan kemampuan peserta melakukan redemonstrasi yang telah diberikan oleh narasumber.

Pelaksanaan kegiatan pengabdian ini dipengaruhi oleh:

1. Faktor pendukung a. Adanya dukungan dari pihak Rumah sakit dan fisioterapis dalam pelaksanaan kegiatan pengabdian.

b. Sarana dan prasarana mampu mendukung kegiatan.

c. Peserta sangat antusias dalam kegiatan.

2. Faktor penghambat

Evaluasi tidak maksimal dilakukan dalam pendampingan fisioterapis secara langsung kepada pasien Nyeri Pada Kasus Carpal Tunnel Syndrome.

\section{Kesimpulan}

Pelaksanaan

masyarakat dalam rangka meningkatkan kemampuan fisioterapis rumah sakit terhadap mengurangi nyeri pada penderita kasus Carpal Tunnel Syndrome (CTS) dengan Nerve Gliding Exercise Exercise dan Ultra Sound (US). Dapat disimpulkan berhasil sampai tahap kemampuan untuk mengaplikasikan. Keberhasilan ini ditunjukkan antara lain:

a. Adanya kesesuaian materi dalam mengatasi masalah di Rumah sakit mengenai Pemberikan nerve gliding exercise dan ultra sound terhadap penurunan nyeri kasus carpal tunnel syndrome.

b. Adanya respon yang positif dari peserta yang ditunjukkan dengan pertanyaan dan tanggapan yang diberikan selama kegiatan

c. Sebanyak $94 \%$ peserta mengalami peningkatan nilai post test.

\section{Ucapan Terima Kasih}

Pengabdi menyampaikan ucapan terima kasih kepada:

1. Lembaga Penelitian dan Pengabdian Kepada Masyarakat (LPPM) Institut Kesehatan Medistra Lubuk Pakam

2. Direktur Rumah Sakit Granmed Lubuk Pakam

3. Kepala Poli Fisioterapi Rumah Sakit Grandmed Lubuk Pakam

\section{Daftar Pustaka}

Bahrudin, M., Lystianto, R., Perdana, P., Fitra, H., Sultana, A., Kedokteran, 
Received: 16 June 2021 :: Accepted: 16 June 2021 :: Published: 30 June 2021

F., ... Sumbersari, S. A. (2015). Pemetik Daun Teh. 114-118.Lü, H., Lee, R. P., Huang, J., Chen, J., Go, V. L. W., Li, Z., \& Lu, Q. Y. (2020). A new HPLC-UV method for the quantification of terpenoids and antioxidant activity of commercial loquat leaf tea and preparation. Journal of Food Measurement and Characterization, 14(2), 10851091.

Ballestero-Pérez, R., Plaza-Manzano, G., Urraca-Gesto, A., Romo-Romo, F., Atín-Arratibel, M. de los Á., PecosMartín, D., ... Romero-Franco, N. (2017). Effectiveness of Nerve Gliding Exercises on Carpal Tunnel Syndrome: A Systematic Review. Journal of Manipulative and Physiological Therapeutics, 40(1), 50-59.

Depkes RI. 2013. Peraturan Menteri Kesehatan Republik Indonesia Nomor 80 Tahun 2013 tentang Penyelenggaraan Pekerjaan dan Praktik Fisioterapis. Jakarta: Depkes RI.

Kaur, P., Kumar, S., \& Arora, L. (2016). Effect of Tendon and Nerve Gliding In Carpal Tunnel Syndrome: Clinical and Electrophysiological Examination. International Journal of Healthcare Sciences, 4(1), 108115.

Kim S. Efficacy of tendon and nerve gliding exercises for carpal tunnel syndrome : a systematic review of randomized controlled trials. J Phys Ther Sci. 2015;27:2645-8.

Rica, T. (2013). Kombinasi Intervensi Terapi Latihan Dan Ultrasound (US) Lebih Baik Daripada Masase Dan Ultrasound (US) untuk Penurunan Nyeri pada Kondisi Plantar Fascitis. (Skripsi). Program Studi Fisioterapi, Universitas Udayana, Denpasar, Bali. Diakses 21 November 2013.Prentice, W.E. (2009). Therapeutic modalities for sports medicine and athletic training (6th Ed.). New York: McGraw-Hill Compa
Salawati, L. (2014). CARPAL TUNEL SYNDROME. (1), 29-37.

Sekarsari, D., pratiwi, arum, \& Farzan, A. (2017). Hubungan Lama Kerja, Gerakan Repetitif Dan Postur Janggal Pada Tangan Dengan Keluhan CTS(Cts) Pada Pekerja Pemecah Batu Di Kecamatan Moramo Utara Kabupaten Konawe Selatan Tahun 2016. Jurnal Ilmiah Mahasiswa Kesehatan Masyarakat Unsyiah, 2(6), 1-9. 